\title{
A denúncia política na origem do new journalism: o caso pioneiro de Rodolfo Walsh
}

\section{The political denoucement at birth of new journalism: the pioneering case of Rodolfo Walsh}

\author{
João Figueira*
}

*Universidade de Coimbra/CEIS20, Portugal

Resumo

\begin{abstract}
Quinze anos antes da obra seminal de Tom Wolfe caraterizar o new journalism e com uma década de avanço sobre "A sangue frio", de Truman Capote, o jornalista e escritor argentino Rodolfo Walsh publicou "Operação massacre", a primeira de três investigações jornalísticas, que verdadeiramente marca o nascimento do novo jornalismo. Partindo de uma releitura crítica sobre o new journalism, mostramos como esta corrente nasceu fora nos Estados Unidos e como só a hegemonia da língua inglesa explica que o fenómeno seja, geralmente, focado na realidade norte-americana, ignorando outras experiências anteriores. O presente artigo deixa ainda evidente a dimensão política do trabalho jornalístico de Walsh, que constitui uma marca diferenciadora face à maioria dos autores norte-americanos do new journalism.
\end{abstract}

Palavras-chave: New journalism; narrativa; "Operação massacre"; Rodolfo Walsh.

Abstract

Fifteen years before Tom Wolfe's seminal work featuring the new journalism and with a decade in advance on Truman Capote's "Cold Blood," argentine journalist and writer Rodolfo Walsh published "Operation massacre", its first of three journalistic investigations that truly mark the birth of the new journalism. Starting from a critical reading about the new journalism, we show how this current was not born in the United States and how only the hegemony of the english language explains that the phenomenon is generally focused on the north american reality, ignoring other experiences. The present article also makes clear the political dimension of Walsh's work, which is a distinguishing mark compared to other authors of the new journalism.

Keywords: New journalism; narrative; "Operation massacre"; Rodolfo Walsh.

Submitted: 12th September 2018

Accepted: 10th December 2018

\section{Introdução}

O jornalista e escritor argentino, Rodolfo Walsh ${ }^{1}$, publicou em 1957, primeiro na imprensa e logo a seguir em livro, a reportagem "Operação massacre". Trata-se de um meticuloso trabalho de investigação sobre o fuzilamento clandestino de um grupo de cidadãos comuns ocorrido no ano anterior, em José Léon Suárez, na área metropolitana de Buenos Aires. A "execrável matança", na expressão de Walsh (1957, apud 2010, p. 215), fora totalmente silenciada, a ponto de os media não quererem saber nada sobre ela, mesmo

\footnotetext{
${ }^{1}$ Nascido na região da Patagónia argentina, Rodolfo Walsh (1927-1977) foi tradutor, escritor e jornalista. Em 1950, o júri, onde estavam Jorge Luis Borges e Adolfo Bioy Casares, atribui-lhe o primeiro prémio de contos policiais. É considerado um nome incontornável na literatura argentina e um dos autores-chave no cruzamento entre jornalismo e literatura. Para Eduardo Galeano, Rodolfo Walsh foi um historiador do seu tempo e o melhor escritor da sua geração.
} 
quando, meses mais tarde, ele apareceu com dados até então desconhecidos e altamente comprometedores para com os militares e o poder político:

essa é a história que escrevo no calor do momento de uma tirada, para que não me tomem a dianteira, mas que depois se vai amarrotando em meu bolso a cada dia que passa, porque passeio com ela por toda Buenos Aires e ninguém quer publicá-la, quase mesmo tomar conhecimento dela (Walsh, 2010, p. 16).

Ele próprio se surpreendeu e sentiu vergonha com tamanho desinteresse quando, exceção feita ao que viria a publicar, concluiu, após pesquisa nos arquivos dos jornais, que tal estória "não existiu nem existe" (Walsh, 2010, p. 16). Receosa de um poder que, após ter deposto Juan Domingo Perón, em 1955, banalizara o uso da violência contra qualquer atitude oposicionista ou mais crítica, a grande imprensa argentina, subserviente e temerosa, não só ignorou o sucedido, como não queria desafiar a força do general Pedro Aramburu, o presidente que dominava o país com pulso de aço (Castro, 2010).

Assim se explica que tenha sido graças à coragem e disponibilidade de dois pequenos órgãos de comunicação, que Rodolfo Walsh conseguiu trazer a público a sua investigação. Primeiro nas páginas do Revolución Nacional (entre janeiro e março de 1957) e depois na revista Mayoria (de maio a julho), Walsh foi publicando a estória que durante meses toda a imprensa séria voluntariamente calou e, por isso, afirma, "senti vergonha" (Walsh, 1957 apud 2010, p. 215). Em novembro do mesmo ano sai a $1^{\text {a }}$ edição em livro, com o título, "Operação massacre. Um processo que não foi encerrado". Em 1964 sai uma 2a edição da obra, com o nome, "Operação massacre e o dossiê Livraga". É, todavia, a terceira versão, editada em 1969 (que já vai em mais de 40 edições), chamada "Operação massacre"2, que temos por referência e seguimos neste trabalho. 0 qual, como se observará, quer na resistência à sua publicação, quer quanto ao tema, revela-nos um fragmento impressionante da realidade política dura e complexa da Argentina da segunda metade da década de 1950.

Em rigor, aliás, uma boa parte da história do século XX da Argentina é marcada por uma sucessão de golpes de estado, que foram mantendo o país sob regimes ditatoriais. Entre as décadas de 50-70, período durante o qual o autor escreve os seus principais trabalhos jornalísticos até ao seu assassinato, em 1977, a Argentina vive entre revoltas e revoluções, o que significa a presença e apetência constante dos militares pela presidência. O percurso de Rodolfo Walsh não fica indiferente ao clima de violência e de impunidade do Estado. Embora o seu envolvimento político conheça várias mudanças são, sobretudo, as questões de caráter ou, para utilizar a expressão de Burgh (2008) quando se refere ao trabalho do jornalismo de investigação, é a ideia de "responsabilidade social" (p. 73) que emerge e se autonomiza na reportagem e na visão de Walsh.

A partir de "Operação massacre" - o "livro-bomba", na expressão de Molina \& Goldoni (2010, p.8) - tudo muda na vida e na obra de Walsh (Brizuela, 2010; Castro, 2010). Doravante, "deixaram de ser as pessoas comuns que povoam os livros de mistério e passaram a ser gente envolvida, direta ou indiretamente, em política: operários, sindicalistas, militares, pistoleiros, advogados, ministros de Estado" (Castro, 2010, p.

\footnotetext{
${ }^{2}$ A obra foi de tal forma marcante que, em 1971, cerca de 30 atores aceitaram participar, clandestinamente, nas filmagens da versão cinematográfica dirigida por Jorge Cedrón.
} 
276). Também por este motivo é legítimo suscitar a dúvida sobre a fronteira entre o Walsh jornalista e o Walsh militante, que Brizuela (2010) suscita e à qual também procuraremos responder. A pertinência da pergunta, aliás, inscreve-se na linha questionadora das reflexões de Luppi (2010), centradas na análise da receção literária de Rodolfo Walsh, em que se insere o trabalho que aqui é analisado, nas quais defende a importância do modo como se lê e interpreta a receção da obra face à imagem do escritor. No caso de "Operação massacre", o autor insiste na mesma justificação, desde a $1^{a}$ edição do livro:

reitero que esta obra não persegue um objetivo político, nem muito menos pretende avivar ódios completamente estéreis. Persegue - um entre muitos - um objetivo social: o aniquilamento, em curto ou longo prazo, dos assassinos impunes, dos torturadores, dos 〈〈técnicos» da picana ${ }^{3}$ que permanecem apesar das mudanças de governo, do submundo armado e uniformizado (Walsh, 1957 apud Walsh, 2010, p. 214).

É dentro desta linha de pensamento, marcada pela "indignação diante do atropelo, da covardia, do assassinato" (Walsh, 1957 apud Walsh, 2010, p. 206), que ele decide assumir uma identidade falsa e mergulhar num processo de investigação que durou cerca de um ano. "Investiguei e relatei estes fatos assombrosos para levá-los ao conhecimento do público da forma mais ampla possível, para que inspirem espanto, para que nunca mais tornem a se repetir" (Walsh, 1957 apud Walsh, 2010, p. 206). Os factos dizem respeito a uma dúzia de cidadãos, quase todos sem ligações a quaisquer forças ou movimentos políticos, que na noite de 9 de junho de 1956 se reuniram na casa de um deles para ouvir na rádio um importante combate de boxe e acabaram presos e fuzilados numa lixeira. Nem todos, como se verá mais adiante, por inépcia dos militares. É esse detalhe que vai possibilitar a reportagem de Walsh, quando seis meses mais tarde, entre duas cervejas, no bar onde costumava jogar xadrez à noite, uma voz lhe sopra a informação: "um fuzilado está vivo" (Walsh, 2010, p. 15). O jornalista estremece, pela novidade e pela recordação súbita que aquela Ihe traz, quando meio ano antes, naquele mesmo local, o teve de abandonar aos repelões e ziguezagues, por causa de um forte tiroteio. Era a repressão a uma tentativa de contragolpe peronista, e a pretexto dele, sem que nada soubessem sobre o que se passava, várias pessoas morrem e outras são levadas presas e fuziladas.

Três dias depois Walsh está diante da sua primeira fonte de informação, um improvável sobrevivente que carrega sinais evidentes de violência no rosto: "o buraco na bochecha, o buraco maior na garganta, a boca estralhaçada e os olhos opacos, onde ficou pairando uma sombra de morte. (...) Assim nasceu aquela investigação (Walsh, 2010, p. 15).

Todas as caraterísticas do new journalism, que 15 anos mais tarde Tom Wolfe vai tipicar na sua obra seminal, estão já presentes neste trabalho de Walsh que, como nos seguintes - "O caso Satanowsky"

\footnotetext{
${ }^{3}$ Instrumento de tortura, com o qual se aplicavam choques elétricos, que foi bastante utilizado desde a década de 1930.
} 
(1958) 4 e "Quem matou Rosendo?" (1969) - têm a denúncia de situações de violência política como tema central. Em todos eles, Walsh usa as técnicas narrativas do que ficará conhecido por new journalism, com o objetivo principal de denúncia e de problematização política e social de uma sociedade em convulsão, como era a realidade argentina daqueles anos, e não como exercício de estilo ou ativismo político, como procuramos mostrar.

Na impossibilidade, por razões de espaço, de nos debruçarmos sobre os três trabalhos de Walsh, vamos centrar-nos no primeiro deles pelos seguintes motivos essenciais: 1) por ser o que inaugura, na verdade, um novo estilo jornalístico; 2) por ser o trabalho que marca a trajetória política de Walsh; 3) e porque é de todas as peças jornalísticas que publicou em livro a que maior número de edições, no país e no estrangeiro, conheceu, logo, também, a mais influente e relevante.

É objetivo do presente artigo mostrar que o new journalism, antes de emergir nos Estados Unidos e de se expandir como fenómeno norte-americano, surgiu primeiro na Argentina, expressou-se em castelhano e teve em Rodolfo Walsh o seu pioneiro. Para tal, procederemos a uma releitura crítica do new journalism, com base em literatura de referência, e à análise comparativa de "Operação massacre" com a tipologia proposta por Tom Wolfe no âmbito da caraterização da corrente conhecida por new journalism.

Complementarmente, observaremos a singularidade da vertente político na obra de Rodolfo Walsh e se "Operação massacre" obedece aos critérios e valores do jornalismo de investigação à luz do conceito de jornalismo investigativo proposto por Burgh (2008a, 2008b), ou se é um texto de pura denúncia política.

\section{New journalism: um conceito esquivo}

A expressão new journalism ${ }^{6}$ tem sido, ao longo dos anos, caraterizada por uma certa imprecisão de fronteiras e até de definições. Ela é utilizada com sentidos e significados diferentes pelo menos desde finais do século XIX (1880-1900), quando à época o crítico e poeta inglês Matthew Arnold a empregou para expressar as enormes transformações e vitalidade que a imprensa vivia e onde se destacava o trabalho do jornal Pall Mall Gazzette (López, 2001 ; Chillón, 1999, apud Cuartero Naranjo, 2017). Com ele e seus principais concorrentes emergia o que ficou conhecido pelo jornalismo muckraker, caraterizado pela

\footnotetext{
${ }^{4}$ Desvenda o assassinato do advogado Marcos Satanowsky, ocorrido em junho de 1957, no âmbito do litígio jurídico pela propriedade do jornal La Razón. Walsh publica na revista Mayoría, entre junho e dezembro de 1958, um conjunto de trabalhos que mostram a responsabilidade das forças armadas e dos serviços secretos no assassinato do advogado, provando que não se tratou de um simples "caso de polícia", como foi inicialmente caraterizado pela generalidade da imprensa, mas de um crime de contornos políticos claros. Como antes sucedera com "Operação massacre", mais uma vez a violência de estado volta a estar no centro deste trabalho de investigação jornalística, também editado em livro, em 1973, embora com algumas alterações relativamente ao conteúdo dos textos publicados, em 1958.

${ }^{5}$ Conjunto de textos inicialmente publicados no semanário CGT, tendo por pano de fundo o assassinato do sindicalista Rosendo Garcia, secretário-adjunto da União Operária Metalúrgica (da CGT), na noite de 13 de maio de 1966, que as autoridades judiciais e policiais não desvendaram. Três anos depois, Walsh desmonta, em poucos meses, o puzzle, apontando o nome do secretário-geral da CGT, Augusto Vandor como autor do crime. O trabalho de Walsh, na linha narrativa das anteriores reportagens de investigação, assume mais uma vez a problematização do tema, mergulhando nos dramas e contradições do movimento sindical peronista. Além de Rosendo, outros dois sindicalistas foram mortos, 0 que empresta ao caso a complexidade político-sindical, que os crimes, resultado de um forte tiroteio na pastelaria Real, de Buenos Aires, nunca mereceram. Daí a incompreensão e até as críticas que alguns intelectuais publicamente lhe dirigiram, sob o argumento de que as denúncias sobre um setor sindical pudessem ser aproveitadas pelo regime contra o movimento operário. Esta investigação jornalística está também publicada em livro, cuja $1^{a}$ edição é de 1969.

${ }^{6}$ Será utilizada a expressão em inglês por ser a mais conhecida e genericamente empregue, seja em trabalhos académicos, seja no campo jornalístico.
} 
investigação de temas sociais, de corrupção e exploração infantil, e que marcaria o panorama jornalístico dos Estados Unidos, desde o início do século, até à I Grande Guerra7.

Ronald Weber (1974) defende que o termo new journalism é vago e escorregadio e Murphy (1974) argumenta que, embora a expressão tenha ganho grande popularidade, nem sempre é utilizada nos mesmos contextos e com os mesmos significados. Bak (2011), no ensaio que realizou para analisar o fenómeno do jornalismo literário segundo as diferentes perspetivas de cada país, conclui que o new journalism é uma construção cultural, afirmando que a sua compreensão e entendimento está diretamente ligado à cultura jornalística de cada contexto.

Um artigo de Anne C. Heinz publicado em 1967, mas exclusivamente pensado e dirigido "para exprimir as novas formas de ensino do jornalismo nos liceus" (Murphy, 1974, p. 2), é um dos muitos exemplos dessa diversidade. Outro exemplo é o modo indiferenciado como os termos new journalism e literary journalism têm sido usados ao longo dos anos (Herrscher, 2016 ; Pauly, 2014 ; Sims, 2007), inclusive por Gay Talese, um dos pioneiros do new journalism norte-americano.

O modo como críticos, estudiosos e escritores têm falado e escrito sobre o new journalism é, pois, muito diverso, sendo "alternadamente usado como 〈〈género», 〈<estilo〉〉 ou 〈〈forma〉" (Nelson, 2017, p. 16). Esta diversidade é bem sublinhada por MacDougall (1972) no prefácio à sexta edição da sua obra, Interpretative Reporting, ao referir as múltiplas etiquetas e rótulos dados ao new journalism: participativo, ativista, humanista, interpelador e advocatício. Norman Sims considera-o um campo dos estudos do jornalismo literário. Na obra que escreveu sobre os 100 anos do jornalismo literário, Sims (2007) dedica, de resto, apenas um - o último - capítulo ao new journalism. É perante esta diversidade de abordagens e de entendimentos que Tom Wolfe afirma que não se sabe com precisão quando e quem cunhou a expressão new journalism:

Seymour Krim diz-me que ouviu essa expressão pela primeira vez em 1965, quando era editor do Nugget e Pete Hamill o chamou para dizer que queria um artigo intitulado $\ll<0$ Novo Jornalismo» sobre pessoas como Jimmy Breslin e Gay Talese. Foi no final de 1966 que se começou a ouvir as pessoas falarem de «Novo Jornalismo» em conversa, pelo que posso lembrar. Não sei ao certo. Para dizer a verdade, nunca gostei da expressão (Wolfe, 1973, p. 38).

Independentemente da incerteza quanto à origem da designação, a verdade é que tem havido um grande consenso quanto à localização e emergência do new journalism, em torno das revistas norte-americanas, Esquire, The New Yorker, Rolling Stone e Harper's (Naranjo, 2017 ; Wolfe, 1973), assim como não tem suscitado a mínima controvérsia a ideia de que é nas décadas de 60 e 70 do século passado que se afirmam os nomes e os trabalhos que vão marcar a nova forma de fazer jornalismo.

Entendido, inicialmente, como uma reação à escola objetivista que à época marcava a prática jornalística, o new journalism constituiu uma nova aragem face ao tédio que os leitores sentiam, perante uma literatura ainda muito presa a fórmulas antigas e ao "tom de beije pálido", na expressão de Tom Wolfe (1976, p.30), do jornalismo dominante. Este ambiente de desencanto, por parte dos públicos, era igualmente sentido por

\footnotetext{
${ }^{7}$ A revista semanal Collier's, fundada em abril de 1888 por Peter Fenelon Collier, emigrante de origem irlandesa, foi o principal título do chamado "muckraker journalism", nos EUA.
} 
vários jornalistas e editores mais criativos e desejosos de tornar os seus textos mais vibrantes, realistas e capazes de romper com o marasmo reinante (Pauly, 2014 ; Wolfe, 1976).

É neste contexto que vai emergir o new journalism, que Wolfe não considera um movimento, por não existir qualquer tipo de relação, de manifesto ou até de identidade entre os diversos autores, razão pela qual o designamos por fenómeno. Inspirados na técnica do realismo literário de autores como Dickens, Gogol ou Balzac, alguns repórteres passaram a usar com perícia os recursos do romance realista, que tanto surpreenderam Wolfe, em 1962, quando leu na Esquire um extenso Perfil sobre o antigo boxeur Joe Louis. A sua primeira reação foi a de que o jornalista - Gay Talese - tinha inventado descrições e diálogos (Wolfe, 1976), dada a maneira tão detalhada e minuciosa como cada frase estava construída ${ }^{8}$. É um facto que isso se passou com outros repórteres que, ao ficcionarem a realidade, levaram a sua subjetividade ao ponto de inventarem personagens e diálogos num claro desrespeito para com as normas e os princípios do jornalismo (Fishkin, 1985). Nestes casos, já nem é de subjetividade que se trata, mas de pura invenção. Em The journalistic Imagination, Richard Keeble (2007), tendo o new journalism e a obra de Capote, $A$ sangue frio, como linha de raciocínio, problematiza as noções de autenticidade e factualidade. Em seu entender, por vezes a retórica da imaginação jornalística não leva em conta esses conceitos e, quando assim é, a ideia de veracidade fica posta em causa ${ }^{9}$.

\section{Quatro recursos técnicos para uma narrativa}

A nova técnica de contar estórias jornalísticas assentou, de acordo com Tom Wolfe (1976), no desenvolvimento de quatro recursos narrativos. Os primeiros dois dizem respeito à construção cena a cena da ação que se quer contar e ao trabalho apurado dos diálogos dos diferentes personagens, como estratégia de maior envolvimento do leitor. O terceiro recurso, chamado,

o ponto de vista da terceira pessoa, visava apresentar cada cena, através dos olhos de uma personagem particular, de forma a dar ao leitor a sensação de estar dentro da cabeça do respetivo personagem e, dessa maneira, experienciar a realidade emocional nos termos em que ela a vive (Wolf, 1976, p. 51).

\footnotetext{
${ }^{8}$ O texto foi publicado em junho de 1962, na revista Esquire, sob o título, "Joe Louis: the King as a middle-age man". Integra a coletânea de trabalhos do jornalista, Fame and Obscurity editada em 1970 e cuja versão em português, já com quatro edições no Brasil, aqui citamos como exemplo das descrições minuciosas que tanto surpreenderam Wolfe: "Joe Louis é viciado em televisão, explicou ela a seus amigos, acrescentando que havia um aparelho até no banheiro, acima da banheira; o aparelho fica numa posição tal que permite a Joe, quando está no chuveiro no outro extremo do banheiro, olhar por cima da cortina e ver a tela da televisão num espelho colocado estrategicamente" (Talese, 2011, p. 461).

9 The New York Review of Books e o Columbia Journalism Review foram duas vozes muito críticas do new journalism, que classificavam de "parajornalismo", tendo publicado ataques violentes contra Talese, Breslin, Wolfe e Dick Schaap, entre outros. Autores como Fishkin (1985) não deixaram também de evidenciar algumas fragilidades e falta de rigor jornalístico, apontando "O canto do carrasco", de Norman Mailer (que na edição portuguesa, Livros de Bolso EuropaAmérica, 1979, tem 2 volumes) como um exemplo onde a precisão foi preterida a favor do embelezamento narrativo. Posteriormente, também John Hersey, num ensaio publicado em 1980 numa coletânea sobre jornalismo, acusa Capote, Wolfe e Mailer de falta de precisão e de truncarem diálogos, considerando que tais falhas e fragilidades éticas do ponto de vista jornalístico só podem ser entendidas à luz da competição entre três escritores que procuram contar as estórias mais impactantes fazendo uso de todos os recursos narrativos possíveis.
} 
Finalmente, o quarto recurso preocupava-se com os detalhes simbólicos das personagens e dos cenários da ação, como o

registo dos gestos, hábitos, maneiras, costumes, estilos de mobília, roupas, decoração, maneiras de viajar, comer, manter a casa, modo de se comportar com os filhos, com os empregados, com os superiores (Wolfe, 1976, p. 51),

entre todo um vasto conjunto de elementos capazes de transmitir o estatuto social, económico e até cultural das personagens envolvidas na narrativa. São esses pormenores, mais do que quaisquer outras palavras, que darão ao leitor a noção acerca dos padrões de comportamento e o lugar no mundo, das pessoas em causa. "O registo desses detalhes não é um adorno ou embelezamento supérfluo na prosa", explica Wolfe (1976, p. 52), para quem tais recursos narrativos, funcionando como polos de atração à leitura, aproximam o texto jornalístico do romance realista.

\section{Um estilo novo numa sociedade em mudança}

Esta nova forma de fazer reportagem (e de escrever Perfis), embora não sendo uma completa novidade ${ }^{10}$, constitui uma clara mudança (no estilo e na forma) face ao jornalismo dominante ou tradicional, no quadro de uma sociedade - norte-americana - também ela a viver profundas mudanças sociais, políticas e culturais. E como tudo o que gera mudança ou põe em causa a normalidade vigente, o new journalism não foi exceção. "Em 1966, o Novo Jornalismo já pagara à vista seus tributos literários: especificamente, amargura, inveja e ressentimento", sublinha Wolfe (2005, p. 41), ilustrando a sua observação com as classificações de "prosa de enchimento" e "prosa espevitada sobre gente inconsequente", com que John Leonard (The New York Book Review) e Renata Adler (New Yorker), respetivamente, chamavam ao novo fenómeno jornalístico (Wolfe, 2005, p. 63).

Renata Adler"11 é autora da reportagem "Letter from Selma" publicada a 10 de abril de 1965 na New Yorker, sobre a célebre marcha liderada por Martin Luther King, de Selma para Montgomery. À jornalista, que acusava muitos dos autores do new journalism de inventarem citações, interessavam-lhe mais as questões

\footnotetext{
${ }^{10}$ A reportagem de John Hersey, "Hiroshima", que preenche toda a edição de 31 de agosto de 1946, da New Yorker, é considerada por vários autores como antecedente direta do new journalism, não apenas pelas caraterísticas narrativas e de estilo que antecipa, mas pela "grande influência" (Wolfe, 2005, p.75) que exerceu em Truman Capote. Hersey nunca gostou dessa colagem, visto que foi um crítico acérrimo do new journalism, no qual encontrava falhas de rigor e alguma invenção. Antes, Joseph Mitchel, também para a mesma revista, publicara em dezembro de 1942 um Perfil intitulado, "Professor sea gull" que, a par de outros trabalhos seus das décadas de 50 e 60, o colocam também na genealogia dos antecedentes diretos do new journalism. Exterior à realidade norte-americana, nas primeiras décadas do século XX, Albert Londres, um dos maiores repórteres franceses de sempre, assinou trabalhos memoráveis, de que sobressaem os publicados pelo Petit Parisien, sobre os cárceres na Guiana francesa e sobre os alienados nos asilos, que depois daria origem ao livro, "Com os loucos". A estes nomes podemos ainda juntar o de Martha Gelhorn, cujas reportagens, quer na guerra civil espanhola, quer na II Grande Guerra, estão longe do jornalismo "objetivo" para se aproximarem das caraterísticas narrativas e autorais que vão enformar o new journalism. Assim se percebe que Tom Wolfe entenda que 0 new journalism não é algo "realmente novo" (2005, p. 68), no sentido em que ele já fervilhava, embora sem assumir, como sucederá a partir do final dos anos 60, a personalidade de um fenómeno mais amplo e de clara rotura.

${ }^{11}$ Muitas das suas reportagens e artigos estão reunidos na coletânea, "After the Tall Timber: Collected Nonfiction," editada pela The New York Review of Books Classics.
} 
coletivas e, sobre o estilo, focava-se mais nos seus interlocutores, que na ideia de criar um estilo próprio ou escrever sobre ela enquanto narradora, como a generalidade dos cultores do new journalism fazia.

$\mathrm{Na}$ verdade, tanto Capote, como Wolfe ou Norman Mailer, fixavam-se, sobretudo, nas caraterísticas psicológicas dos seus entrevistados ou interlocutores, nas questões da contra-cultura que marcavam a transição dos anos 60 para os 70 nos Estados Unidos, nunca deixando de vincar os seus pontos de vista, até porque o respetivo autor, quase sempre, estava no centro da estória (Herrscher, 2016; Boynton, 2005). As suas reportagens ou Perfis, dada a intensidade narrativa que apresentavam, liam-se como se fossem contos. Todavia, o foco dos trabalhos, em que o autor nunca deixava de estar presente, dava em certos aspetos razão às críticas de Renata Adler, no sentido em que Ihes importava mais o estilo que a denúncia ou a discussão das questões de dimensão coletiva, como preferia aquela jornalista.

Nada disso, no entanto, coloca em causa ou diminui a profundidade dos trabalhos desses jornalistas que corporizam o fenómeno do new journalism, designadamente, o travo literário com que eram construídos. No fundo, contavam a realidade com as armas e os instrumentos da literatura, na feliz expressão de Roberto Herrscher (2016). Ou, como este mesmo professor das universidades de Barcelona e Columbia escreve, para explicar o método utilizado por Truman Capote, em $A$ sangue frio, e a sua obsessão relativamente aos detalhes e à precisão da narrativa: "que sintamos como leitores que estivemos lá e que vimos tudo" (Herrscher, 2016, p. 256). A estória de Truman Capote, primeiro publicada em capítulos no outono de 1965 na revista New Yorkere em livro em abril do ano seguinte, é a peça final e definitiva do que ficaria cunhado por new journalism:

O próprio Capote não chamava seu livro de jornalismo; longe disso; dizia que tinha inventado um novo género literário, "o romance de não ficção". Porém, seu sucesso atribuiu uma força esmagadora àquilo que logo viria a ser chamado de Novo Jornalismo (Wolfe, 2005, p. 46).

Pouco depois, em 1973, Tom Wolfe escrevia a obra que "vem sendo considerada a bíblia do new journalism, ao fazer a história do seu aparecimento e apresentar os seus princípios orientadores" (Boynton, 2005, p. XVI). Contudo, 15 anos antes do livro seminal de Tom Wolfe e com uma década de antecedência face $A$ sangue frio, a Argentina assistia à publicação da reportagem que, verdadeiramente, marca o nascimento do new journalism.

\section{Walsh: jornalista pioneiro e militante de esquerda}

Na noite de 9 de junho de 1956, 12 homens foram fuzilados, em José Léon Suárez, na área metropolitana de Buenos Aires, sem acusação formal ou julgamento. O país vivia a chamada "Revolução Libertadora" iniciada um ano antes, com a queda de Juan Domingo Perón. Em consequência da radicalização política, o uso da violência tinha-se banalizado e é no contexto da repressão a uma tentativa de contragolpe peronista que o referido grupo de homens, na maioria trabalhadores sem ligações a quaisquer movimentos ou partidos políticos, é preso e fuzilado - quando, afinal, se tinham reunido na casa de um deles para ouvirem a transmissão radiofónica do combate de boxe para atribuição do título de campeão sul-americano. 
Seis meses depois, a 18 de dezembro, no bar onde costumava jogar xadrez com os amigos, um homem confidencia a Walsh que um dos fuzilados está vivo. O jornalista sobressalta-se e, durante um ano, deixará a casa e a família, assume a identidade falsa de Francisco Freyre (com documentação igualmente falsificada), arranja um revólver e vai morar para o bairro operário onde os 12 homens haviam sido presos e depois levados num camião para fuzilamento. Ao longo dos meses de investigação jornalística a que se dedicou, descobriu que afinal havia sete sobreviventes, três deles refugiados na Bolívia, todos, porém, vivendo a sua clandestinidade e escondidos da polícia.

Com base, inicialmente, no testemunho de Carlos Livraga, um dos sobreviventes atingido por duas balas, que denunciou o comandante da ação, Walsh dá início ao processo de investigação (consultando também os autos de detenção) que o irá conduzir à descoberta e ao encontro de outras vítimas que, por inépcia dos militares, conseguiram escapar à morte. O trabalho final culmina com a reconstituição dos diálogos daquela noite de junho, com as descrições minuciosas de tudo quanto se passou, dos ambientes em que toda ação teve lugar e com a apresentação de provas que demonstram que a prisão do referido grupo foi ilegal, ilícita e anterior à declaração da lei marcial.

Rodolfo Walsh publica, entre janeiro e março de 1957, seis artigos no jornal Revolución Nacional, a que se seguem, entre maio e julho do mesmo ano, outros nove textos, agora publicados na desaparecida revista Mayoria. Em novembro sai uma $1^{a}$ edição do livro, sob o título, "Operação massacre. Um processo que não foi encerrado". Nela, Walsh esclarecia que a publicação da investigação que fizera correspondia a uma "necessidade de revelar a verdade" (Brizuela, 2010, p. 266) e não movido por intenções políticas ou ideológicas - que as tinha e as declarava, mas que neste caso eram secundárias.

Até que ponto, no entanto, é possível desligar o Walsh jornalista, do cidadão e militante de esquerda, como ele mesmo se define no Prólogo da 10 edição do livro, em 1957? Nessa altura, era ainda um forte opositor de Juan Perón, de cuja ação e pensamento se irá, anos depois, aproximar. Antes, porém, apoiara, em 1955, a Revolução Libertadora que derrubara Perón, da qual, no entanto, já não esconde o seu desencanto, quando da publicação de "Operação massacre". As questões de caráter sobrepõem-se, na sua obra jornalística, aos aspetos políticos. Foi assim, em "Operação massacre", como será depois com "Quem matou Rosendo?", que vai colher a incompreensão e a crítica de muitos sectores, que interpretaram esta reportagem como um perigoso ataque ao movimento sindical. Walsh, no entanto, entendia que "dentre as diferenças que separam os homens as partidárias talvez sejam as mais superficiais. Outras são as diferenças que importam: as irreparáveis, irredutíveis diferenças de caráter" (1957, apud, 2010, p. 206).

Na Introdução à primeira edição de "Operação massacre", a qual volta a ser publicada nas edições seguintes, Walsh justifica, de resto, porque motivo, sendo de esquerda, colabora e publica as suas peças em órgãos de direita: "porque eles ousam, e nesse momento não reconheço nem aceito hierarquia mais alta que a da coragem civil. Ou pretenderão que silencie estas coisas por ridículos preconceitos partidários?" (1957, apud, 2010, p. 206). O jornalista referia-se às sucessivas recusas de vários jornais em publicar a reportagem inicial sobre Carlos Livraga, sua fonte de informação inicial. O trabalho acabou sendo aceite pelo semanário Revolución Nacional. Sob o título, "Eu também fui fuzilado", o jornalistas dá início à publicação de um conjunto de reportagens, que vão depois prosseguir na revista Mayoría. Para si, o fundamental era que a investigação viesse a público e os factos revelados: "todo aquele que me ajudar a difundi-los e divulgá-los será para mim um aliado, a quem não questionarei por suas ideias políticas" (Walsh, 1957, apud Walsh, 2010, p. 206) 
É neste contexto que devem ser entendidas as suas palavras quando afirma depois que, "como jornalista, a política não me interessa muito" (Walsh, 1957, apud, Walsh, 2010, p. 213). Só assim se percebe, aliás, a espécie de pulsão jornalística na forma como persistiu na publicação da reportagem, apesar das várias recusas que foi colecionando, até encontrar alguém com "coragem de publicá-la e iniciar com ela a série de artigos e reportagens sobre os fuzilamentos" (Walsh, 1957, apud Walsh, 2010, p. 213).

Não é, todavia estranho à sua condição de homem de esquerda o facto de ter estado em Cuba logo no início da revolução e de ter integrado, com García Márquez, o primeiro grupo de jornalistas da agência Prensa Latina, fundada por Che Guevara. A Walsh se deve, de resto, fruto da sua paixão pela criptografia, o fracasso norte-americano na Baía dos Porcos, em abril de 1961, ao ter decifrado um telegrama pretensamente de caráter comercial, mas que continha pormenores sobre a planeada invasão a Cuba. De volta à Argentina, a sua militância ativa é intensa e variada. Funda a revista CGT, órgão semanal da Confederação Geral dos Trabalhadores, onde publicou as primeiras peças de "Quem matou Rosendo?". Está, ainda ligado à fundação da Agência de Notícias Clandestinas (ANCLA), que pertencia às forças peronistas de quem se tinha aproximado, a que se segue, como "montonero", a formação de jornalistas populares. "Walsh foi-se radicalizando politicamente a partir de «Operação massacre», até entrar, em 1973, para a organização Montoneros, depois de deixar as Forças Armadas Peronistas, nas quais ingressara provavelmente em algum momento de 1971" (Brizuela, 2010, p. 266).

Natalia Brizuela, professora de Cultura e Literatura latino-americanas contemporâneas na Universidade de Berkeley (Califórnia) e estudiosa do autor argentino, considera que a produção do Walsh político começa com "Operação massacre" e termina 20 anos depois com a "Carta aberta à junta militar". A 25 de março de 1977, depois de ter distribuído por amigos e enviado por correio, para as redações locais e correspondentes de media estrangeiros, uma carta aberta dirigida à junta militar liderada pelo general Videla que, na véspera, tinha cumprido um ano na Casa Rosada, após mais um golpe militar ter mudado a presidência - neste caso, deposto Maria Estela Perón ${ }^{12}$-, Rodolfo Walsh foi cercado numa rua de Buenos Aires, morto a tiro e o seu corpo levado para nunca mais aparecer. Nessa carta, que fica como o seu derradeiro ato político, o jornalista e escritor faz um ataque severo e frontal a toda a política levada a cabo pela junta militar, ao mesmo tempo que denuncia o estendal de atrocidades e restrições a todos os tipos de liberdades:

em um ano, os senhores reduziram o salário real dos trabalhadores em $40 \%$, diminuíram sua participação na renda nacional em 30\% e aumentaram de seis para dezoito horas a jornada de trabalho que um operário necessita para pagar a cesta básica, ressuscitando assim formas de trabalho forçado que não subsistem nem mesmo nos últimos redutos coloniais. Congelando salários a coronhadas enquanto os preços sobem pela ponta das baionetas, abolindo toda a forma de reclamação coletiva, proibindo assembleias e comissões internas, aumentando os turnos de trabalho, elevando o desemprego ao índice recorde de $9 \%$ e prometendo superá-lo com 300 mil novas demissões, os senhores fizeram que as relações de produção regredissem aos

\footnotetext{
${ }^{12}$ Viúva de Juan Domingo Perón, falecido em 1974. Regressado do exílio em junho de 1973 para concorrer às eleições, ganhou-as com $62 \%$ dos votos. Falecido em julho do ano seguinte, Maria Estela Perón (popularmente conhecida e tratada por Isabel Perón), que era vice-presidente, assumiu o cargo do marido, até o golpe militar do general Videla a ter deposto. Foi a primeira mulher a ascender à presidência da Argentina.
} 
primórdios da era industrial, e quando os trabalhadores quiseram protestar, qualificaram-nos de subversivos, sequestrando comissões inteiras de delegados que em certos casos apareceram mortos e noutros não apareceram (Walsh, 1977, apud Walsh, 2010, p. 254).

Esta foi a última peça do Walsh político, cujo perfil e travo narrativo não deixa de nos remeter para outros textos de denúncia igualmente marcantes, como "J'accuse", de Émile Zola, ou para a "Carta ao general", do dramaturgo espanhol Fernando Arrabal, dirigida ao ditador Francisco Franco. É, no entanto, com "Operação massacre" que começa o percurso mais empenhado politicamente do jornalista argentino, embora o que marca e distingue, verdadeiramente, esse trabalho é o facto de ele ter sido pioneiro (e fundador) do fenómeno designado por new journalism, como vamos poder observar nos pontos seguintes.

\section{"Retórica da factualidade" na construção da reportagem}

"Operação massacre" está dividida em três partes: I)as pessoas; II) os fatos; III) a prova. Diferentemente dos trabalhos que uma década depois vão emergir nos Estados Unidos, os de Walsh não se limitam às descrições subjetivas e psicológicas dos seus personagens; ao desenvolvimento de um estilo narrativo de travo literário; ou ao jornalismo "embedded", hoje tão em voga nas sofisticadas operações militares, mas que nos anos 60 e 70 John Sack, Plimpton e Hunter Thompson, entre outros, usaram, respetivamente, para escrever sobre treino militar, futebol americano ou motoqueiros (Wolfe, 2005).

Em Walsh há investigação jornalística cuidada, profunda, paciente, meticulosa, detalhada e por isso todos os dados são objeto de reconfirmação, para dar ao leitor o máximo de informação verdadeira, mostrar-lhe quem são, como são, o que pensam e como se comportam as personagens e, ainda, para o transportar para o centro da ação:

casa de rapagões valentes e ambiente talvez tempestuoso, esta dos Garibotti no bairro operário de Boulogne. O pai, Francisco, é um homem e tanto: alto, musculoso, rosto quadrado e enérgico, olhos um pouco hostis, bigode fino caído sobre os cantos da boca. A mãe também é uma bela mulher, embora de traços duros e plebeus. Alta, resoluta, boca desdenhosa e olhos que não sorriem (Walsh, 2010, p. 29).

A atitude dos guardas, antes despreocupada, agora é rude, carrancuda. Vozes, ruídos de passos na galeria adquirem singulares ressonâncias. Depois, prolongados silêncios. Alheio a tudo, esparramado num banco, como um grande Netuno negro, o sargento Díaz ronca estrondosamente. Seu amplo tórax sobe e desce em ritmo pausado. 0 sono pinta em seu rosto uma máscara impassível. Os outros começam a olhá-lo com fastio, com espanto. (Walsh, 2010, p. 85).

Num lampejo de lucidez, dom Horacio compreende. O tiro de misericórdia. Estão revistando um a um os corpos e executando os que dão sinais de vida. E agora. Sim, 
agora chegou a sua vez. A caminhonete se aproxima. O chão, sob os óculos de don Horacio, desaparece em incandescências de giz. Estão a iluminá-lo, estão apontando para ele. Não os vê, mas sabe que apontam para sua nuca. Esperam um movimento. Nem por isso, talvez. Talvez atirem do mesmo jeito. Talvez estranhem justamente que ele não se mexa. Talvez descubram aquilo que é evidente, que ele não está ferido, que não sangra em parte nenhuma do seu corpo. Uma náusea espantosa revira-lhe o estômago. Consegue sufocá-la nos lábios. Quisera gritar. Uma parte do seu corpo os pulsos apoiados no chão como alavancas, os joelhos, a ponta dos pés - quisera escapar enlouquecida. Outra - a cabeça, a nuca - repete: não se mexa, não respire. (Walsh, 2010, p. 108).

Em toda esta "retórica da factualidade", na expressão de Richard Keeble (2007, p. 9), é o conteúdo que está ao serviço da forma e não o oposto. Por outro lado, os seus personagens, em "Operação massacre", são cidadãos comuns vítimas de violência por parte do estado, o que aumenta, perigosamente, o risco da investigação, ao qual não é alheio o facto de, para isso, Walsh ter assumido uma identificação falsa. Finalmente, mas não menos importante, todos os seus trabalhos de investigação jornalística, e este em particular, culminam com a revelação de dados (e as respetivas provas), até então escondidos, ignorados ou desconhecidos:

Essas pessoas existiram, portanto, e entre elas estava Livraga. Mas afirmei que ele [0 chefe da polícia] prendeu esses homens antes da entrada em vigor da lei marcial ${ }^{13}$. E, a fim de determinar a hora em que foi promulgada a lei, não me limitei a consultar os jornais de 10 de junho de 1956, que, unânimes, informam que ela foi anunciada à Oh30 daquele dia. Fui mais longe, busquei o livro de locutores da Rádio do estado e o fotocopiei, a fim de provar, com precisão de minutos, que a lei marcial passou a vigorar à 0 h32 do dia 10 de junto. (Walsh, 2010, p. 151).

O rigor jornalístico que impõe aos seus trabalhos e a preocupação pela verdade factual do que afirma, no sentido de que não reste a menor dúvida ao leitor de que tudo quanto escreve não resulta das suas convicções ou opinião pessoal, mas que é fruto da investigação e confirmação de dados, nunca deixam de estar presentes. Este breve trecho que acabamos de reproduzir é bem elucidativo quanto aos seus métodos de pesquisa e de escrita, ao partilhar com o leitor - e na primeira pessoa - como conseguiu saber o que afirma e de que forma acedeu à informação que veicula. Em "Operação massacre", a confirmação definitiva e irrefutável de que o fuzilamento fora um ato ilegal residia, justamente, na possibilidade de provar a discrepância horária entre o momento da detenção do grupo de 12 homens, alegadamente ligados ao movimento de insurreição, e a declaração oficial da lei marcial. O que começou por ser uma denúncia jornalística acabou, por força dela, ser posteriormente confirmado pelo próprio chefe da polícia, Fernández

\footnotetext{
${ }^{13}$ Walsh conseguiu junto de um funcionário da estação oficial de rádio, cópia do documento que comprova a hora exata em que foi promulgada a lei marcial (anunciada ao país aos seus microfones), dado decisivo para provar que as prisões dos 12 homens são anteriores a esse momento. $\mathrm{O}$ funcionário seria despedido por esse facto.
} 
Suárez, quando, perante a Junta Consultiva da província, reunida em sessão à porta fechada, declarou: "às 23 horas dei busca pessoalmente naquela propriedade" (Walsh, 2010, p. 151).

Outro exemplo pela obsessão de comprovar a veracidade de tudo quanto relata está bem visível no modo como descreve os primeiros momentos em que Dom Horacio, que sobreviveu ao fazer-se de morto, decide após várias horas deitado, ensaiar a fuga do local onde se encontrava e em cuja narrativa surge mais uma vez a voz do narrador:

Levantou a cabeça e viu o campo todo branco. Divisou uma árvore solitária no horizonte. Nove meses mais tarde, verificaria com surpresa que se tratava não de uma única árvore, mas de ramagens de várias que, tapadas por uma ondulação do terreno, produziam aquela ilusão de ótica. Incidentalmente, esse detalhe provou a este que escreve - caso ainda restasse alguma dúvida - que Dom Horacio tinha estado ali. 0 único local de onde se pode observar essa estranha miragem é o cenário do fuzilamento (Walsh, 2010, p. 117).

Novamente a preocupação pelo rigor e pela verdade e que a eventual ausência de um e de outra jamais possam pairar no pensamento do leitor. Para que tal não suceda, Walsh volta a partilhar, agora em nota de rodapé, como chegou à certeza de que o que escreve é factual: depois de contar ao jornalista as suas primeiras impressões ao levantar-se do solo, Walsh pediu-lhe que fosse com ele ao local para fazer uma reconstituição desses instantes iniciais. Foi nessa altura que Dom Horacio percebeu que aquilo que ao princípio Ihe parecera uma árvore eram, afinal, ramagens. E o jornalista reconfirmava que aquele fora, na verdade, o local do fuzilamento (Walsh, 2010, pp.117-118).

\section{Contar o acontecido com "as armas da literatura"}

A subjetividade jornalística e a dimensão psicológica das personagens que caraterizam o new journalism estão, igualmente, presentes ao longo de todo o texto de Walsh, cujo início também está longe de corresponder à pirâmide invertida que marcava o jornalismo tradicional contra o qual a nova corrente construiu o seu caminho:

Nicolás Carranza não era um homem feliz nessa noite de 9 de junho de 1956. Protegido pelas sombras, acabava de entrar em casa e talvez viesse remoendo algo por dentro. Nunca saberemos ao certo. Os homens levam para o túmulo muitos pensamentos amargos, e no túmulo de Nicolás Carranza a terra já está ressecada. Por um momento, no entanto, conseguiu esquecer suas preocupações. Após o sobressaltado silêncio inicial, um coro de vozes estridentes se elevou para recebê-lo. (Walsh, 2010, p. 25).

Assim começa "Operação massacre", introduzindo o primeiro personagem ao leitor, sem esquecer de o mostrar também no seu contexto familiar, ao mesmo tempo que deixa cair algumas pistas acerca de sua clandestinidade: 
Nicolás Carranza tinha seis filhos. Os menores talvez tenham-se enroscado em suas pernas. A maior, Elena, quem sabe pôs a cabeça ao alcance da mão do pai. A pequenina Julia Renée - de apenas quarenta dias - dormitava no berço. Sua companheira, Berta Figueroa, ergueu os olhos da máquina de costura. Sorriu-lhe, com uma mistura de compaixão e alegria. Era sempre igual. Seu homem chegava sempre assim: fugitivo, noctívago, passageiro. Às vezes ficava uma noite, depois desaparecia semanas (Walsh, 2010, p. 25).

O frequente recurso a analepses e prolepses dão à reportagem uma clara densidade e plasticidade narrativas. Sem nunca deixar de ser jornalismo, embora usando os instrumentos da literatura, é esta nova dimensão narrativa que empresta a todo o trabalho de Walsh, aquilo que anos mais tarde Tom Wolfe caraterizará como sendo "uma questão de personalidade, de energia, de tendência, de bravura... numa palavra, de estilo" (2005, p. 32), ao referir-se ao new journalism.

Rodolfo Walsh começa, na verdade, por nos apresentar alguém que, logo no primeiro parágrafo, nos diz que já morreu - embora não saibamos como nem quando - , mas cujos passos, dúvidas e pensamentos seguimos com o narrador. Pouco depois, sem nos ter sido dito, ainda, o que se passou - e que é o centro e razão de ser da reportagem - o jornalista, numa prolepse, informa que algo de importante se vai ali passar, sem, todavia, dizer o quê, para nos oferecer, primeiro, o quadro social de Florida:

O bairro onde ocorrerão tantas coisas imprevistas está a umas seis quadras da estação, indo para oeste. Oferece os violentos contrastes das zonas em desenvolvimento, onde confluem o residencial e o esquálido, o sobrado recém-construído e o terreno coberto de mato e latas. $O$ habitante médio é um homem de trinta a quarenta anos que possui casa própria, com um jardim que cultiva nos momentos de ócio, e que ainda não terminou de pagar o empréstimo bancário que Ihe permitiu adquiri-la. Vive com uma família não muito numerosa e trabalha em Buenos Aires como empregado no comércio ou operário especializado (Walsh, 2010, p. 33).

Também quando, através da construção cena a cena, vai dando ao leitor o essencial de cada personagem e nos apresenta "Giunta, ou don Lito, como é chamado no bairro, volta de Villa Martelli, onde passou a tarde com os pais" (Walsh, 2010, p. 37), o jornalista repete o recurso à prolepse, agora para nos informar que tal personagem, não se sabe ainda como, não será uma das vítimas do fuzilamento e, ainda, como aparenta ser tão diferente de todas as outras:

De todas as testemunhas que sobreviverão ao drama, nenhuma resultará tão convincente, a nenhuma será tão fácil e tão natural evidenciar a sua inocência, mostrála como algo concreto e tangível. Basta conversar com ele uma hora, ouvi-lo rememorar, observar a indignação e o renovado espanto que paulatinamente lhe brotam de dentro, assomam a seus olhos e chegam a eriçar os seus cabelos, para deixar de lado qualquer incredulidade (Walsh, 2010, p. 37). 
À medida que o leitor vai conhecendo melhor don Lito e as suas caraterísticas, fruto do seu ofício de empregado de comércio numa sapataria, o repórter ora usa o presente, ora antecipa o futuro, como forma de adensar o fio condutor da estória e, com isso, aumentar também a sua intensidade dramática que aumenta com as detenções:

Não suspeita - enquanto janta nessa casa acolhedora, adquirida com seu esforço, rodeado pelo afecto dos seus - que horas mais tarde essas qualidades o ajudarão a superar o transe mais amargo de sua vida (Walsh, 2010, p. 38).

A atitude dos guardas da escolta é correta ou despreocupada. Alguns prisioneiros conversam uns com os outros.

- Por que nos levam presos? - indaga um.

- Sei lá... - responde outro. Talvez por jogar baralho.

- Não me cheira bem. O grandalhão disse qualquer coisa sobre uma revolução. Os mais desconcertados são dom Horacio e Giunta. Pois eles nem baralho jogavam. Gavino, que não os conhece mas poderia esclarecê-los, guarda silêncio. Aturdido e descabelado, enxugando o sangue dos lábios, ele sabe por que os levam presos (Walsh, 2010, p. 74).

O recurso a diálogos realistas, cuja reconstituição, por não ter assistido a eles - como Capote fará várias vezes, em " A sangue frio"14 - , só foi possível realizar através das entrevistas e cruzamento de informações que efetuou junto dos intervenientes que sobreviveram ao fuzilamento, é outra das marcas de "Operação massacre" e uma das caraterísticas do new journalism apontadas por Tom Wolfe.

Antes, porém, do diálogo entre dois dos presos - e da informação que dá sobre um terceiro, calado, mas que sabe o que os outros desconhecem, o que adensa o mistério -, Walsh já revelara pormenores que aqueles detidos desconheciam, ao mesmo tempo que faz o enquadramento político e histórico da ação. Ou seja, o leitor sabe mais e está mais bem informado que os próprios personagens:

longe dali, a verdadeira rebelião arde furiosamente.

Em junho de 1956, o peronismo, deposto nove meses antes, fez sua primeira tentativa séria de retomar o poder mediante uma revolta de base militar com algum apoio ativo de civis. A proclamação assinada pelos generais Valle e Tranco fundamentava a rebelião numa descrição exata do estado de coisas. (Walsh, 2010, p. 70).

Fazendo uso de planos narrativos diferenciados, como se estivesse a escrever um romance, o jornalista não procura apenas dizer o que sabe que se passou. Di-lo gradual e paulatinamente, mas de modo a emprestar ao texto a intensidade dramática, o suspense e a curiosidade próprias da literatura. Mais importante do que

\footnotetext{
${ }^{14}$ Em entrevista dada a George Plimptom (New York Times Book Review), quando questionado como poderia ter reconstituído diálogos de Nancy Clutter, um das quatro vítimas, se ela estava morta - ou até as conversas entre Dick e Perry, antes de cometerem os assassínios - Capote respondeu que em todos os casos procurou quem pudesse corroborar ou contar o que escreveu.
} 
contar "o quê", na linha do jornalismo convencional da pirâmide invertida, o new journalism concentra-se especialmente no "como" e no "porquê" dos acontecimentos e das personagens. São esses aspetos que emprestam densidade à narrativa, tornando-a diferente e mais interessante, ao mesmo tempo que permite que o jornalista penetre na esfera mais pessoal e por isso psicológica dos intervenientes na estória. Este tipo de reportagem investe com particular cuidado na dimensão subjetiva do jornalista, reforçando o caráter autoral do respetivo trabalho, sem que isso implique baixar a guarda face ao rigor e à verdade jornalística. Tais estratégias narrativas possibilitam, depois, que o leitor saiba como os intervenientes pensam, que se sinta no próprio cenário da ação e, sobretudo, que a veja e a perceba sob diferentes perspetivas, uma vez que o recurso, por parte do jornalista, ao ponto de vista da terceira pessoa - ao apresentar cada cena por intermédio dos olhos de um personagem - tem por objetivo dar a quem lê a reportagem a sensação de experimentar "a realidade emocional" (Wolfe, 2005, p. 54) vivida pelo próprio interveniente.

\section{Conclusão}

As reportagens de Rodolfo Walsh inserem-se na linha do melhor jornalismo de investigação, de que "Operação massacre" é o seu primeiro e mais eloquente exemplo. A tragédia humana, corporizada por cidadãos comuns vítimas dos diferentes poderes - político, militar ou sindical ou coniventes entre si constitui o principal veio narrativo, no qual Walsh foi capaz de fundir o rigor da linguagem e a espessura dramática da narrativa, com a denúncia de casos de manifesta atualidade jornalística e interesse público. A estrutura narrativa que introduz em 1957, com "Operação massacre", compreende já todos os recursos e técnicas que 15 anos mais tarde Tom Wolfe vai tipificar como caraterísticas do new journalism: 1) a construção cena a cena aliada ao trabalho apurado dos diálogos; 2) o chamado ponto de vista da terceira pessoa; 3) e o registo meticuloso e pormenorizado dos hábitos, gestos, modo de ser e de estar, mas também do comportamento, de cada personagem.

O resultado é uma narrativa não ficcionada - mas sim verdadeira, palpável e verificável, construída com os instrumentos do romance realista, mas seguindo princípios jornalísticos, porque

além das questões de técnica, existe uma vantagem tão óbvia, tão interna, que quase se esquece o poder que ela tem: o simples facto de o leitor saber que tudo aquilo realmente aconteceu (Walsh, 2010, p. 57)

E o que aconteceu e o jornalista reconstitui revela-nos uma estória intensa, tocante, plena de humanismo e de revolta, por parte do autor:

se há algo que justamente procurei suscitar nestas páginas, foi o horror das revoluções, cujas primeiras vítimas são sempre os inocentes, como os fuzilados de José León Suárez ou aquele conscrito abatido a poucos metros de onde eu estava. A gente do povo não morre gritando «〈Viva a Pátria!»), como nos romances. Morre vomitando de medo, como Nicolás Carranza (Walsh, 1957 apud Walsh, 2010, p. 239) 
Em "Operação massacre", o jornalista não apenas estriba toda a narrativa em dados confirmados e verificáveis, como apresenta elementos novos, fruto da sua própria investigação jornalística. Se do ponto de vista formal podemos dizer que a narrativa de Rodolfo Walsh antecipa as que mais tarde vamos ler em Truman Capote, Norman Mailer, Gay Talese, Breslin e Tom Wolfe, entre muitos outros, ela, todavia, se distingue de todas as norte-americanas num ponto central e nuclear: as reportagens do jornalista e escritor argentino são trabalhos de investigação jornalística e, no caso de "Operação massacre", trata-se da denúncia de crimes de estado. Esta dimensão política está, aliás, presente em todos os seus trabalhos, uma vez que tanto o que vai publicar no ano seguinte, "O caso Satanowsky", como, em 1969, "Quem matou Rosendo?" mantêm essa caraterística comum. Observamos, assim, que a matéria central em Rodolfo Walsh (de pendor claramente político), afasta-se claramente dos eixos temáticos dominantes que encontramos no new journalism norte-americano. Facto que facilmente se compreende: enquanto um emergiu e desenvolveu-se em democracia, o caso argentino é marcado pelo clima de ditadura que o país vivia.

Robert Boynton, focado exclusivamente na realidade dos Estados Unidos, sublinha, de resto, essa ideia "apolítica" dos autores do new journalism do seu país, ao realçar que autores como Kramer, Talese e Trillin são, de alguma forma, os mais antigos representantes de uma fileira de repórteres que passaram grande parte das suas carreiras a escrever sobre "as vidas extraordinárias de pessoas comuns, e as vidas comuns de pessoas extraordinárias" (2005, p. XXVII).

Convém, no entanto, deixar claro que as referidas reportagens de Walsh, não obstante o seu foco vincadamente político e, nessa medida, constituírem importantes exemplos de resistência e denúncia, cumprem rigorosamente todos os requisitos do jornalismo de investigação. Olhá-las como se fossem simples trabalhos de militância política é desqualificar o trabalho jornalístico feito com total independência e que tais reportagens indiscutivelmente possuem. No caso de "Operação massacre", a investigação levada a cabo por Rodolfo Walsh é uma busca permanente pelos factos, pela descoberta e divulgação de provas que revelam como tudo se passou naquela noite de 9 de junho de 1956. Natalia Brizuela, que como vimos antes entende que toda a produção de Walsh, a partir de "Operação massacre", tem uma dimensão e assunção políticas claras, não hesita em dizer que aquela reportagem de 1957 é, essencialmente, um apurado trabalho jornalístico cujo principal objetivo foi "revelar a verdade sobre fuzilamentos clandestinos, assassinatos sem punição judicial" (Brizuela, 2010, p. 260).

A análise que fazemos à reportagem de Walsh coincide com a apreciação feita pela investigadora de Berkeley. Desde a sua estrutura narrativa até ao seu processo de investigação, que visa obter provas sobre a ilegalidade dos fuzilamentos, para concluir que estes foram cometidos sobre cidadãos inocentes e que tiveram lugar antes da declaração oficial da lei marcial pela rádio, todo o trabalho jornalístico revela-nos: 1 ) uma reportagem suportada em factos; 2) cada informação é confirmada e explicitada como o autor chegou até ela; 3) a voz do jornalista é substituída pelas vozes, pelos olhares e pelas emoções dos diferentes personagens da narrativa, com o objetivo de transportar o leitor para o interior da ação e, dessa maneira, fornecer-Ihe o máximo de informação possível; 4) o jornalista não faz juízos de valor nem expressa a sua opinião; 5) a crueza da narrativa, quando existe, surge estribada em factos e nunca por força de uma adjetivação gratuita ou por intermédio de artificialidades descritivas.

Confrontando o trabalho de Walsh com a conceção de jornalismo de investigação de Burgh (2008a, 2008b), aquilo que observamos nesta reportagem é a "procura pela mais completa versão da verdade" (p. 20) e "ir atrás daquilo que alguém quer esconder" (p. 17). De acordo, ainda, quantos aos métodos e finalidades do 
jornalismo investigativo, reparamos que há total coincidência entre os resultados e processos de Walsh com as noções defendidas por Hugo de Burgh (2008a): denúncia de abusos de poder, desafiar as versões oficiais, desvendar verdades ocultas e questionamento dos factos. Mais: o jornalista "até pode simpatizar com as vítimas, mas a primeira tarefa não é simpatizar, mas compreender" (Burgh, 2008b, p. 85), atitude que Walsh assume ao longo de todo o trabalho, confirmando e reconfirmando dados, contextualizando cada momento e cada interveniente da ação que descreve. Por outro lado, se o jornalismo de investigação, como defende Burgh (2008a), tem o dever de "olhar além do que é convencionalmente aceitável, por trás das interpretações dos fatos que são fornecidos pelas autoridades e pelo autoritarismo, e apelar para o nosso bom senso de justiça" (p. 3), o trabalho de "Operação massacre" contém e reflete todos esses aspetos, confirmando-o como reportagem de investigação, a que não falta, ainda, a noção de "responsabilidade social" (Burgh, 2008b, p. 73) tanto no discurso profissional, como no papel do jornalista desempenhado por Walsh.

É também neste sentido que vão as palavras de Brizuela (2010), quando diz que embora "Operação massacre" seja hoje considerado um marco no cruzamento do jornalismo com a literatura, o autor faz mesmo questão em "se afastar da literatura porque a intensidade e a ilegalidade da violência perpetrada pelas forças militares simplesmente não podiam ser escritas como ficção, como literatura" (Brizuela, 2010, p. 260).

Precisamente por se tratar de uma dura realidade, é que Walsh se mostrou desiludido com o resultado nulo da reportagem de "Operação massacre", uma vez não ter tido qualquer impacto nos planos judicial ou político. Isto é, ninguém reconheceu que "naquela noite de 10 de junho de 1956, em nome da República Argentina, cometeu-se uma atrocidade" (Walsh, 1964 apud Walsh, 2010, p. 242). O que reflete a enorme fragilidade do jornalismo em contextos de ditadura ou de democracias débeis. Cenário que contrasta com o quadro político norte-americano onde o new journalism ganhou esporas de cidadania e, por via de uma hegemonia linguística, se afirmou como corrente inovadora e inspiradora. Não podemos, no entanto, deixar de estranhar que os seus teóricos e estudiosos tenham vindo ao longo dos anos a ignorar esta experiência precursora e o nome do seu autor. O presente artigo mostra que uma década antes de Capote publicar "A sangue frio" já Walsh o tinha escrito, e que a "Operação massacre" é, de facto, uma reportagem pioneira no quadro do conceito do new journalism.

\section{Bibliografia}

Bak, J. S. (2011). Introduction. In J. S. Bak y B. Reynolds, Literary Journalism across the globe: Journalistic traditions and transnational influences. USA: University of Massachusetts Press.

Boynton, R. S. (2005). The New New Journalism. Conversations with america's best nonfiction writers on their craft. New York: Vintage Books.

Brizuela, N. (2010). Rodolfo Walsh: entre a literatura e a política. In R. Walsh, Operação massacre (pp. 259270). São Paulo: Companhia das Letras.

Burgh, H. de (2008a). Um nível elevado de honestidade? In Hugo de Burgh (Org.), Jornalismo investigativo (pp. 3-28). São Paulo: Roca. 
Burgh, H. de (2008b). Considerações sobre jornalismo investigativo. In Hugo de Burgh (Org.), Jornalismo investigativo (pp. 73-97). São Paulo: Editora Roca.

Capote, T. (2006). A sangue frio. Lisboa: Dom Quixote.

Castro, R. (2010). Rodolfo Walsh: triunfo sobre a morte. In R. Walsh, Operação massacre (pp. 271-282). São Paulo: Companhia das Letras.

Cuartero Naranjo, A. (2017). The concept of new journalism and its adaption to narrativa journalism in Spain. Doxacomunicacion, 2, 43-62.

Chillón, A., \& Bernal. S. (1985). Periodismo informativo de creación. Barcelona: Mitre.

Fishkin, S. F. (1985). From fact to fiction : Journalism and imaginative writing in America. Baltimore: Johns Hopkins University Press.

García, V. (2014). Caso Satanovsky, de Rodolfo Walsh: de la prensa al livro à quince años de distancia. VI Congresso Internacional de Letras, Transformaciones culturales. Debates de la teoría, la crítica y la linguística (pp. 711-719). Disponível em: http://letras.filo.uba.ar/sites/letras.filo.uba.ar/files/documentos/GARC\%C3\%8DA ACTAS 2014.p df.

Herrscher, R. (2016). Periodismo narrativo: como contar la realidade con las armas de la literatura. Buenos Aires: Marea.

López, G. G. (2001). Desinformação e os limites da informação. Lisboa: Folhas \& Letras.

Luppi, J. P. (2010). Obra abierta. Sobre la recepción literaria de Rodolfo Walsh hacía la década del 90. IV Congresso internacional de Letras Transformaciones culturales: Debates de la teoria, la critica y la linguística en el Bicentenario (pp. 2238-2244). Buenos Aires. Disponível em: http://eventosacademicos.filo.uba.ar/index.php/CIL/IV2010/paper/viewFile/2948/1364

Keeble, R. (2007). On journalism, creativity and the imagination. In R. Keeble \& S. Wheeler (eds), The journalistic imagination (pp. 1-14). New York: Routledge.

MacDougall, C. D. (1972). Interpretative Reporting. New York: Macmillan.

Murphy, J. E. (1974). The new journalism: a critical perspective. Journalism Monographs. Minneapolis: American Association for Education in Journalism, 34 . Disponível em: https://files.eric.ed.gov/fulltext/ED096677.pdf.

Molina, S., \& Goldoni, R. P. (2010). Apresentação. In R. Walsh, Essa mulher, (pp. 7-14). São Paulo: Editora 34.

Nelson, A. M. (2017). Personal frameworks and subjective truth: new journalism and the 1972 U.S. presidential election. Tese doutoramento. New Zealand: Victoria University of Wellington. Disponível

em: https://researcharchive.vuw.ac.nz/xmlui/bitstream/handle/10063/6703/thesis access.pdf?sequen ce $=1$.

Pauly, J. J. (2014). The New Journalism and the Struggle for Interpretation. Journalism, 15(5), 589-604.

Sims, N. (2007). True stories: a century of literary journalism. Illinois: Northwestern University Press.

Talese, G. (2011). Fama \& anonimato. São Paulo: Companhia das Letras.

Walsh, R. (2010). Operação massacre. São Paulo: Companhia das Letras.

Weber, R. (1974). The reporter as artist: a look at the New journalism controversy. New York: Hastings House. 
Wolfe, T. (2005). Radical Chique e o Novo Jornalismo. São Paulo: Companhia das Letras.

Wolfe, T. (1976). El Nuevo periodismo. Barcelona: Anagrama. 